\title{
Measurement of Radioactivity in Carbonated Soft Drinks and Annual Dose Assessment
}

\author{
Elassaad Jemiii ${ }^{1,2}$, Malek Mazouz ${ }^{2}$ \\ ${ }^{1}$ Physics Department, College of Sciences Al-Zulfi, Majmaah University, Al Majmaah, KSA \\ ${ }^{2}$ Faculté des Sciences de Monastir, Université de Monastir, Monastir, Tunisia \\ Email: *e.jemii@mu.edu.sa
}

How to cite this paper: Jemii, E. and Mazouz, M. (2020) Measurement of Radioactivity in Carbonated Soft Drinks and Annual Dose Assessment. Journal of Environmental Protection, 11, 682-689. https://doi.org/10.4236/jep.2020.119041

Received: February 21, 2020

Accepted: September 7, 2020

Published: September 10, 2020

Copyright (c) 2020 by author(s) and Scientific Research Publishing Inc. This work is licensed under the Creative Commons Attribution International License (CC BY 4.0).

http://creativecommons.org/licenses/by/4.0/

\begin{abstract}
A set of measurements have been conducted, using gamma spectrometry technique, in order to determine the activity-level in some carbonated soft drinks. The obtained activity is about $0.18 \pm 0.07 \mathrm{~Bq} / 1$ for ${ }^{137} \mathrm{Cs}$, whereas it is less than $0.13,0.18$ and $4.51 \mathrm{~Bq} / 1$ respectively for ${ }^{212} \mathrm{~Pb},{ }^{214} \mathrm{~Pb}$ and ${ }^{40} \mathrm{~K}$. The total average annual dose is about 3.49, 1.69 and $1.68 \mu \mathrm{Sv} / \mathrm{y}$ respectively for $7-12$, $12-17$ and $>17$ years old person leading to a radiological risk about 0.142 for adolescent and adults. The obtained results show no significant radiation dose and radiation hazard on human health due to the consumption of these carbonated soft drinks.
\end{abstract}

\section{Keywords}

Gamma-Ray Spectrometry, HPGe Detector, Carbonated Soft Drinks, Effective Dose, Risk Assessment

\section{Introduction}

The main sources of natural radioactivity in the environment are the earth and the atmosphere. ${ }^{232} \mathrm{Th}$ and ${ }^{238} \mathrm{U}$ and their associated progeny (such as ${ }^{214} \mathrm{~Pb},{ }^{212} \mathrm{~Pb}$, ${ }^{214} \mathrm{Bi},{ }^{228} \mathrm{Ac}, \ldots$ ) as well as ${ }^{40} \mathrm{~K}$ are usually the most found natural radionuclides in earth samples. Some artificial radionuclides, such as ${ }^{134} \mathrm{Cs},{ }^{137} \mathrm{Cs},{ }^{90} \mathrm{Sr}$ and ${ }^{131} \mathrm{I}[1]$ [2] could be present with a small activity in food, water or beverages (juices, soft drinks). These artificial radionuclides are a consequence of human nuclear activities. Over the end years, humans are more susceptible to be exposed to these radiations either by inhalation of radioactive gas or by ingestion of food, water and other beverages. When these radionuclides enter into the body, their subsequent decay may damage the cells and affect the human health [3]. Beverages such as fruit juices and carbonated soft drinks are widely consumed nowadays 
and may contain both natural and artificial radionuclides. However, they represent one of the important sources of radioactivity for the consumed. It is then important to know the amount of radionuclides in these products and estimate their potential radiological risk to the human health. Carbonated soft drinks represent one of the important consumed beverages. They contain essentially water (most crucial ingredient), sugar, carbon dioxide and some flavorings and preservatives with different concentrations. Since each person should consume around 2 liters of fluid each day especially in hot weather. The consumption of carbonated soft drinks can help to reach this target and then they represent a positive role in a balanced diet.

Over the end years, the consumption of carbonated soft drinks in the world has been increased [4] especially for adolescents and adults. For example, young adolescents in the low and middle-income countriess reported having consumed soft drinks 1.39 times per day [4]. The consumption rate of the carbonated soft drinks varies from a country to another and the high-income countries, such as USA have the highest consumption rate in the world compared to the other countries [5]. A recent report states that the average annual consumption worldwide of soft drinks is about 11.4 US gallons per person [6], which is quite important to justify, in our opinion, the radiological survey of these products. In this paper, we report the activity-level of gamma emitters radionuclides in some carbonated soft drinks commercialized in Tunisia markets using gamma-ray spectrometry technique. The measurements are then exploited to determine the annual effective dose due to the consumption of these beverages as well as the radiological risk for different age groups.

\section{Materials and Methods}

\subsection{Experimental Setup}

The measurements were performed with the gamma spectrometry technique using a high-purity germanium gamma detector (HPGe). The type of the detector is GMX80P4-95 with a cryostat configuration CFG-PV4. Its relative efficiency is equal to $3 \%$ at $186 \mathrm{keV}$ and its energy resolution (FWHM) is $2 \mathrm{keV}$ at 1.33 $\mathrm{MeV}$. In order to reduce the background radiations, the detector is shielded by $10 \mathrm{~cm}$ of lead with a copper of $3 \mathrm{~mm} \mathrm{[7]} \mathrm{and} \mathrm{it} \mathrm{is} \mathrm{cooled} \mathrm{by} \mathrm{liquid} \mathrm{nitrogen.} \mathrm{The}$ detection chain contains a high voltage power supply powered at $3500 \mathrm{~V}$, a preamplifier and an amplifier (model 2002 Canberra) having a positive polarity, a gain of 1000 and a $2 \mu$ s shaping time. The identification of the obtained peaks and the data analysis was carried out using the Genie 2000 software (Canberra) and ROOT scientific software toolkit [8]. The calibration of both energy and efficiency is carried out using a multi-nuclides standard source [7].

In this work, five samples of carbonate soft drinks (Coca Cola, Fanta, Boga Mint, Viva and Apla) commercialized in Tunisia markets, have been studied. Each sample of $500 \mathrm{ml}$ volume is stored in Marinelli backer. All Marinelli backers were tightly closed and left away about 4 weeks in order to reach a secular 
equilibrium between the parent radionuclides and their progenies, which are used to determine the activity concentration of their parents. The measurement time was set to $t=72 \mathrm{~h}(259200 \mathrm{~s})$ for each sample as well as a distilled water sample in order to ensure a good counting statistic.

The distilled water sample is used as a background sample and its activity-level will be subtracted from the carbonated soft drinks one in order to account for the activity coming from the environment and the gamma absorption effect in the samples.

\subsection{Activity and Annual Dose Calculation}

The specific activity concentration $(A)$ of a given radionuclide present in samples was calculated using the Equation (1) [3] [7]:

$$
A(\mathrm{~Bq} / \mathrm{l})=\frac{N_{s}-N_{B G}}{V t P_{\gamma} \varepsilon_{\gamma}}
$$

where: $N_{s}$ and $N_{B G}$ are the number of counts in the radionuclide photo peak of the carbonated soft drinks and the background respectively, $\varepsilon_{\gamma}$ is the total absorption efficiency, $P_{\gamma}$ is the gamma-ray emission probability of the corresponding gamma-ray energy and $V$ is the volume $(500 \mathrm{ml})$ of each sample. The activity concentration of the present radionuclides was determined using the following gamma lines: $\left(351.9 \mathrm{keV}, P_{\gamma}=35.6 \%\right)$ for ${ }^{214} \mathrm{~Pb},\left(238.63 \mathrm{keV}, P_{\gamma}=\right.$ $43.6 \%)$ for ${ }^{212} \mathrm{~Pb},\left(1460.8 \mathrm{keV}, P_{\gamma}=10.66 \%\right)$ for ${ }^{40} \mathrm{~K}$ and $\left(661.7 \mathrm{keV}, P_{\gamma}=\right.$ $85.1 \%)$ for ${ }^{137} \mathrm{Cs}$.

A check of the presence of many other natural and artificial radionuclides was systematically performed but their specific activities were not reported herein when they are below the minimum detectable activity (MDA) defined by [7]:

$$
\operatorname{MDA}(\mathrm{Bq} / \mathrm{l})=\frac{2.71+4.65 \sqrt{\mathrm{NBG}}}{V t P_{\gamma} \varepsilon_{\gamma}}
$$

The annual effective dose $D(\mathrm{~Sv} / \mathrm{y})$ due to the ingestion of radionuclides present in carbonated soft drinks was calculated using the following equation [7] [9]:

$$
D=A I f
$$

where: $A(\mathrm{~Bq} / \mathrm{l})$ is the specific activity, $I$ is the average annual consumption of carbonated soft drinks (11 gallons per year which is about $441 / y$ ) [6] and $f$ $(\mathrm{Sv} / \mathrm{Bq})$ is the dose conversion coefficient via ingestion whose values, for different age groups, are presented in Table 1 [10].

\subsection{Radiological Risk Assessment}

The radiological hazard due to an internal exposure to a radioactive source is a term used to identify the risk factors that have the potential to cause harm to the human health.

The radiological risk, due to carbonated soft drinks consumption, is calculated using the following equation [3] [7] [11]: 
Table 1. Dose conversion coefficient via ingestion (Sv/Bq) [10].

\begin{tabular}{ccccc}
\hline Age group $(\mathrm{y})$ & ${ }^{212} \mathrm{~Pb}$ & ${ }^{214} \mathrm{~Pb}$ & ${ }^{40} \mathrm{~K}$ & ${ }^{137} \mathrm{Cs}$ \\
\hline $7-12$ & $2.0 \times 10^{-8}$ & $3.1 \times 10^{-10}$ & $1.3 \times 10^{-8}$ & $1.0 \times 10^{-8}$ \\
$12-17$ & $1.3 \times 10^{-8}$ & $2.0 \times 10^{-10}$ & $7.6 \times 10^{-9}$ & $1.3 \times 10^{-8}$ \\
$>17$ & $6.0 \times 10^{-8}$ & $1.4 \times 10^{-10}$ & $6.2 \times 10^{-9}$ & $1.3 \times 10^{-8}$ \\
\hline
\end{tabular}

$$
\text { Risk }=D_{\text {int }} \times S F \times t
$$

where: $D_{\text {int }}=A \times I$ represents the average daily intake of soft drinks expressed in pico-Curie, $S F$ (risk/pCi) is the cancer slope factor (morbidity) and presented in Table 4 and $t$ (365 days) is the exposure duration.

\section{Results and Discussion}

The specific activity concentrations of the different radionuclides found in the studied carbonated soft drinks samples are presented in Table 2. The upper limits of the activities are given within $68 \%$ confidence level. The obtained values indicate that ${ }^{40} \mathrm{~K}$, one of the important elements for the body metabolism, is the major contributor of radioactivity in carbonated soft drinks as it is the case for many other beverages and foods.

The average maximum activity of ${ }^{40} \mathrm{~K}$, detected in three samples, is less than $4.51 \mathrm{~Bq} / \mathrm{l}$. The existence of this natural radionuclide in our samples is essentially due to the mineral water used to prepare these beverages and to the presence of low concentrations of potassium benzoate.

This acid is used to preserve beverages by inhibiting the growth of mold, yeast and some bacteria. The obtained activity concentrations of ${ }^{40} \mathrm{~K}$ is relatively low to other beverages such as coffee, tea or fruit juices [12] [13] [14], which contain a higher amount of rough vegetal products, furthermore it is lower than that reported in Mexico soft drinks [15].

For ${ }^{212} \mathrm{~Pb}$ (progeny of ${ }^{232} \mathrm{Th}$ ) and ${ }^{214} \mathrm{~Pb}$ (progeny of ${ }^{226} \mathrm{Ra}$ ), the specific activity is respectively less than 0.13 and $0.18 \mathrm{~Bq} / \mathrm{l}$. These radionuclides exist in the environment and the soil, where their average activity concentrations are about 32 $\mathrm{Bq} / \mathrm{kg}$ for ${ }^{226} \mathrm{Ra}$ and $45 \mathrm{~Bq} / \mathrm{kg}$ for ${ }^{232} \mathrm{Th}$ according to UNSCEAR [16].

These radionuclides can transfer from soil to fruit fruits or vegetables [17]. Their low transfer factor from the soil to soft drink rough components (fruits, plants and water) explains their low activity concentration in our samples. According IAEA, the mean value of the transfer factor for $\mathrm{Pb}$ from soil to fruit plants at temperate environment, derived from agricultural ecosystem is about 0.015 [18].

The artificial radionuclide ${ }^{137} \mathrm{Cs}$ is detected in the three samples of carbonated soft drinks brands which are all made in Tunisia (Boga mint, Viva and Apla). The obtained specific activities vary from 0.12 to $0.28 \mathrm{~Bq} / 1$ with an average activity of $0.18 \mathrm{~Bq} / \mathrm{l}$. These Tunisian brands are made of local mint, lemon and apple among other components. The existence of this radionuclide is generally due to 
Table 2. Specific activity of the different radionuclides present in the samples.

\begin{tabular}{ccccc}
\hline \multirow{2}{*}{ Samples } & \multicolumn{4}{c}{ Specific Activity (Bq/l) } \\
\cline { 2 - 5 } & ${ }^{137} \mathrm{Cs}$ & ${ }^{40} \mathrm{~K}$ & ${ }^{214} \mathrm{~Pb}$ & ${ }^{212} \mathrm{~Pb}$ \\
\hline 1 & - & $\leq 4.46$ & $\leq 0.22$ & - \\
2 & $0.28 \pm 0.07$ & $\leq 5.51$ & $\leq 0.19$ & $\leq 0.2$ \\
3 & - & - & $\leq 0.14$ & - \\
4 & $0.15 \pm 0.07$ & - & - & $\leq 0.04$ \\
5 & $0.12 \pm 0.07$ & $\leq 3.58$ & - & $\leq 0.15$ \\
Average & $0.18 \pm 0.07$ & $\leq 4.51$ & $\leq 0.18$ & $\leq 0.13$ \\
\hline
\end{tabular}

-: Not detected.

the soil contamination [7] and can be transfer from soil to fruit trees and plants [19]. The mean value of the transfer factor from soil to fruit plants at temperate environment is about 0.021 for Cs [18].

It has to be noticed that the obtained low activities of ${ }^{137} \mathrm{Cs}$ present no potential health hazard to human because of the short biological half-life [20].

The annual effective dose due to the ingestion of the reported radionuclides, for different age groups, is presented in Table 3 . The total average value is about $3.49,1.69$ and $1.68 \mu \mathrm{Sv} / \mathrm{y}$ respectively for $7-12 \mathrm{y}, 12-17 \mathrm{y}$ and more than 17 years old. As stated previously, the major contribution of the total annual effective dose comes from ${ }^{40} \mathrm{~K}$. The maximum annual dose due to ${ }^{40} \mathrm{~K}$, obtained in our case for all age group, is very less than the recommended limit which is about $0.17 \mathrm{mSv} / \mathrm{y}$ [16]. All the obtained annual effective doses are very relatively low to the $1 \mathrm{mSv} / \mathrm{y}$ recommended limit given by the world organizations such as UNSCEAR [16] and ICRP [21].

The last part of the present work is the assessment of the radiological risk due to the consumption of carbonated soft drinks. The obtained values are presented in Table 4. Given that the daily intake of carbonated soft drinks is not exactly reported by any world organization, we have determined the radiological risk assuming that the daily intake is the same for adolescent and adults. The estimated value of $0.142 \times 10^{-6}$ for the total risk is below the recommendation of the excess lifetime cancer risk which is between $10^{-6}$ and $10^{-4}$ [22]. This result indicates clearly that the radionuclides detected in the studied carbonated soft drinks do not present any radiological hazard on human health.

\section{Conclusions}

In this work, we have determined the activity concentrations of radionuclides present in the carbonated soft drinks commercialized in Tunisia markets using the gamma ray spectrometry technique. The results indicate low levels of radioactivity in all the consider samples, which is an expected result given that no any nuclear accident in the origin area of these materials. The annual effective dose, due to the ingestion of the soft drinks, and the radiological risk have been 
Table 3. Annual effective dose ( $\mu$ Sv/y).

\begin{tabular}{cccccc}
\hline Age group & ${ }^{212} \mathrm{~Pb}$ & ${ }^{214} \mathrm{~Pb}$ & ${ }^{40} \mathrm{~K}$ & ${ }^{137} \mathrm{Cs}$ & Total \\
\hline $7-12 \mathrm{y}$ & 0.114 & 0.002 & 2.579 & 0.792 & 3.488 \\
$12-17 \mathrm{y}$ & 0.074 & 0.001 & 1.508 & 0.102 & 1.687 \\
$>17 \mathrm{y}$ & 0.343 & 0.001 & 1.230 & 0.102 & 1.677 \\
\hline
\end{tabular}

Table 4. Risk assessment due to the radionuclides present in the soft drinks.

\begin{tabular}{cccccc}
\hline & ${ }^{212} \mathrm{~Pb}$ & ${ }^{214} \mathrm{~Pb}$ & ${ }^{40} \mathrm{~K}$ & ${ }^{137} \mathrm{Cs}$ & Total Risk $\left(10^{-6}\right)$ \\
\hline Average daily intake (pCi) & 0.423 & 0.585 & 14.679 & 0.585 & \\
Slope factor (risk/pCi) [22] & $2.50 \times 10^{-11}$ & $0.034 \times 10^{-11}$ & $2.47 \times 10^{-11}$ & $3.04 \times 10^{-11}$ & \\
Risk $\left(10^{-6}\right)$ & $0.386 \times 10^{-2}$ & $7.356 \times 10^{-5}$ & 0.132 & $0.650 \times 10^{-2}$ & 0.142 \\
\hline
\end{tabular}

estimated and found below the recommended limits indicating no significant radiological hazard to the consumption of these beverages.

The present work can serve our community as well as the neighboring countries regarding radiological information on the studied carbonated soft drinks especially that is the first time where these products are studied in our country, furthermore, the recommended limit, concerning the carbonated soft drinks, has not been reported so much by the world organizations.

\section{Conflicts of Interest}

The authors declare no conflicts of interest regarding the publication of this paper.

\section{References}

[1] Alharshan, G.A., Aloraini, D.A., Al-Ghamdi, H., Almuqrfin, A.H., Azony, K.M. and Alsalamah, A.S. (2017) Measuring the Radioactivity Concentration of ${ }^{40} \mathrm{~K}$ and ${ }^{137} \mathrm{Cs}$ and Calculating the Annual Internal Doses from Ingesting Liquid and Powdered Milk. Radiochemistry, 59, 98-103. https://doi.org/10.1134/S1066362217010131

[2] Spasova, Y., Wätjen, U. and Altzitzoglou, T. (2008) European Measurement Comparison of ${ }^{137} \mathrm{Cs},{ }^{40} \mathrm{~K}$ and ${ }^{90} \mathrm{Sr}$ in Milk Powder. Journal of Radioanalytical and Nuclear Chemistry, 277, 211-215. https://doi.org/10.1007/s10967-008-0732-5

[3] Jemii, E. and Alharbi, T. (2018) Measurements of Natural Radioactivity in Infant Formula and Radiological Risk Assessment. Journal of Radioanalytical and Nuclear Chemistry, 315, 157-161. https://doi.org/10.1007/s10967-017-5646-7

[4] Yang, L.L., Bovet, P., Liu, Y.X., Zhao, M., Ma, C.W., Liang, Y.J. and Xi, B. (2017) Consumption of Carbonated Soft Drinks among Young Adolescents Aged 12 to 15 Years in 53 Low- and Middle-Income Countries. American Journal of Public Health, 107, 1095-1100. https://doi.org/10.2105/AJPH.2017.303762

[5] Nation Master (2002)

https://www.nationmaster.com/country-info/stats/Lifestyle/Food-and-drink/Soft-dr ink/Consumption

[6] Basu, S., McKee, M., Galea, G. and Stuckler, D. (2013) Relationship of Soft Drink Consumption to Global Overweight, Obesity, and Diabetes: A Cross-National 
Analysis of 75 Countries. American Journal of Public Health, 10, 2071-2077. https://doi.org/10.2105/AJPH.2012.300974

[7] El Mestikou, R., Jemii, E., Mazouz, M., Ben Ali, M. and Ghedira, L. (2018) Determination of the Activity Level in Powdered Milk Available in Tunisia and Assessment of the Radiological Risks. Journal of Radioanalytical and Nuclear Chemistry, 317, 991-996. https://doi.org/10.1007/s10967-018-5965-3

[8] Brun, R. and Rademakers, F. (1997) ROOT-An Object Oriented Data Analysis Framework. Nuclear Instruments and Methods in Physics Research, 389, 81-86. https://doi.org/10.1016/S0168-9002(97)00048-X

[9] Ababneh, Z.Q., Alyassin, A.M., Aljarrah, K.M. and Ababneh, A.M. (2010) Measurement of Natural and Artificial Radioactivity in Powdered Milk Consumed in Jordan and Estimates of the Corresponding Annual Effective Dose. Radiation Protection Dosimetry, 138, 278-283. https://doi.org/10.1093/rpd/ncp260

[10] IAEA Safety Standard (2011) Radiation Protection and Safety of Radiation Source: International Basic Safety Standard. General Safety Requirements. IAEA, Vienna, 206.

[11] Uwatse, O.B., Olatunji, M.A., Khandaker, M.U., Amin, Y.M., Bradley, D.A., Alkhorayef, M. and Alzimami, K. (2015) Measurement of Natural and Artificial Radioactivity in Infant Powdered Milk and Estimation of the Corresponding Annual Effective Dose. Environmental Engineering Science, 32, 838-846. https://doi.org/10.1089/ees.2015.0114

[12] Adeniji, A.E., Alatise, O.O. and Nwanya, A.C. (2013) Radionuclide Concentrations in Some Fruit Juices Produced and Consumed in Lagos, Nigeria. American Journal of Environmental Protection, 3, 37-41. https://doi.org/10.11648/j.ajep.20130202.11

[13] Velasco, H., Cid, A.S., Anjos, R.M., Zamboni, C.B., Rizzotto, M., Valladares, D.L. and Juri Ayub, J. (2013) Variability of ${ }^{137} \mathrm{Cs}$ and ${ }^{40} \mathrm{~K}$ Soil-to-Fruit Transfer Factor in Tropical Lemon Trees during the Fruit Development Period. J Environ Radio, 104, 64-70. https://doi.org/10.1016/j.jenvrad.2011.09.016

[14] Canbazoglu, C. and Dogru, M. (2013) A Preliminary Study on ${ }^{226} \mathrm{Ra},{ }^{232} \mathrm{Th},{ }^{40} \mathrm{~K}$ and ${ }^{137}$ Cs Activity Concentrations in Vegetables and Fruits Frequently Consumed by Inhabitants of Elazığ Region, Turkey. Journal of Radioanalytical and Nuclear Chemistry, 295, 1245-1249. https://doi.org/10.1007/s10967-012-1995-4

[15] Espinosa, G., Ibinarriaga, I.H. and Golzarri, J.I. (2009) An Analysis of the Potassium Concentration of Soft Drinks by HPGe Gamma Spectrometry. Journal of Radioanalytical and Nuclear Chemistry, 282, 401-404. https://doi.org/10.1007/s10967-009-0139-y

[16] UNSCEAR (2008) United Nations Scientific Committee on the Effects of Atomic Radiation (UNSCEAR) Report. UNSCEAR, New York.

[17] Jolly, Y.N., Islam, A. and Akbar, S. (2013) Transfer of Metals from Soil to Vegetables and Possible Health Risk Assessment. SpringerPlus, 2, Atricle No. 385. https://doi.org/10.1186/2193-1801-2-385

[18] IAEA (2010) Handbook of Parameter Values for the Prediction of Radionuclides Transfer in Terrestrial and Freshwater Environments. IAEA, Vienna, $194 \mathrm{p}$.

[19] Carini, F. (2001) Radionuclide Transfer from Soil to Fruit. The Journal of Environmental Radioactivity, 52, 237-279. https://doi.org/10.1016/S0265-931X(00)00035-7

[20] Osibite, O., Olomo, J., Tchokossa, P. and Balogum, F. (1999) Radioactivity in Milk Consumed in Nigeria 10 Years after Chernobyl Reactor Accident. Nuclear Instruments and Methods in Physics Research Section A, 422, 778-783. 
https://doi.org/10.1016/S0168-9002(98)00996-6

[21] ICRP (2007) Recommendation of the International Commission on Radiological Protection. ICRP, Stockholm.

[22] US-EPA (1993) Carcinogenicity Assessment. IRIS Integrated Risk Information System. US Environmental Protection Agency, Washington DC.

http://www.epa.gov/iris 